\title{
NON-SOOTING, LOW FLAME TEMPERATURE MIXING-CONTROLLED DI DIESEL COMBUSTION
}

\author{
Lyle M. Pickett and Dennis L. Siebers \\ Combustion Research Facility, Sandia National Laboratories
}

Methods of producing non-sooting, low flame temperature diesel combustion were investigated in an optically-accessible, quiescent constant-volume combustion vessel under mixingcontrolled diesel combustion conditions. Combustion and soot processes of single, isolated fuel jets were studied after autoignition and transient premixed combustion and while the injector was fully-open (i.e. during the mixing-controlled phase of heat release for diesel combustion). The investigation showed that small injector tip orifices could be used to produce non-sooting and low flame temperature combustion simultaneously. The use of small orifices was shown to enable non-sooting and low flame temperature combustion in two different ways as summarized below. A more detailed description of the experimental methods and results is provided in Ref. [1-3].

First, using an injector tip with a 50 micron orifice and ambient oxygen concentrations as low as $10 \%$ (simulating the use of extensive EGR), a fuel jet was non-sooting at typical diesel ambient temperatures $(1000 \mathrm{~K})$. Second, using the same injector tip at a reduced ambient gas temperature $(850 \mathrm{~K})$, but with $21 \%$ oxygen, it was shown that non-sooting, mixingcontrolled combustion occurred at the lift-off length in a fuelair mixture with a cross-sectional average equivalence ratio of approximately 0.6 - suggesting that the quasi-steady combustion was fuel-lean and thereby avoided the formation of a diffusion flame.

The adiabatic flame temperature with reduced ambient oxygen concentration or fuel-lean combustion was approximately $2000 \mathrm{~K}$, compared to typical diesel flame temperatures that exceed $2600 \mathrm{~K}$. The 50 micron orifice results above were obtained using a \#2 diesel fuel. However, using an oxygenated fuel (20 wt \% oxygen), the investigation showed that the same low temperature combustion, either with reduced ambient oxygen concentration or fuel-lean combustion, was realized with a 100 micron orifice.

Although these single, isolated jets do not have jet-jet interactions that would occur in realistic engines, the results are useful for understanding limiting-case behavior of single-jet mixing and combustion during an injection event. The nonsooting and low flame temperature mixing-controlled combustion realized using small orifice tips suggests that the use of small orifices offers the potential for a simultaneous soot and NOx reduction in an engine, much like diesel HCCI combustion. However, further research is needed to determine whether these methods could be successfully implemented in real engines.

\section{REFERENCES}

1. Pickett, L.M. and Siebers, D.L., "An Investigation of Diesel Soot Formation Processes Using Micro-Orifices," Proc. Combust. Inst. 29:655-662, 2002.

2. Pickett, L.M. and Siebers, D.L., "Non-Sooting, Low Flame Temperature Mixing-Controlled DI Diesel Combustion," Submitted to SAE 2004 World Congress.

3. Siebers, D.L. and Pickett, L.M., "Injection Pressure and Orifice Diameter Effects on Soot in DI Diesel Fuel Jets," Conference on Thermo-fluidynamic Processes in Diesel Engines, Valencia, Spain, 2002. 